Article

\title{
Enhanced Delivery of 4-Thioureidoiminomethylpyridinium Perchlorate in Tuberculosis Models with IgG Functionalized Poly(Lactic Acid)-Based Particles
}

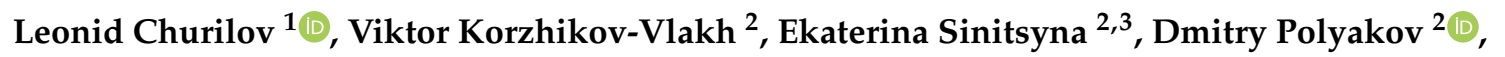 \\ Oleg Darashkevich ${ }^{4}$, Mikhail Poida ${ }^{1}$, Galina Platonova ${ }^{3}{ }^{\mathbb{D}}$, Tatiana Vinogradova ${ }^{5}$, \\ Vladimir Utekhin ${ }^{1}$ (D), Natalia Zabolotnykh ${ }^{5}$, Vsevolod Zinserling ${ }^{1}$, Peter Yablonsky ${ }^{1,5}$, \\ Arto Urtti ${ }^{2}$ and Tatiana Tennikova ${ }^{2, *}$ \\ 1 Faculty of Medicine, Saint Petersburg State University, 7/9 Universitetskaya Embankment, \\ 199034 St. Petersburg, Russia; elpach@mail.ru (L.C.); poidan@mail.ru (M.P.); \\ utekhin44@mail.ru (V.U.); v.zinserling@spbu.ru (V.Z.); glhirurgb2@mail.ru (P.Y.) \\ 2 Institute of Chemistry, Saint Petersburg State University, 7/9 Universitetskaya Embankment, \\ 199034 St. Petersburg, Russia; v.korzhikov-vlakh@spbu.ru (V.K.-V.); kat_sinitsyna@mail.ru (E.S.); \\ ravendoctor@mail.ru (D.P.); arto.urtti@helsinki.fi (A.U.) \\ 3 Institute of Macromolecular Compounds, Russian Academy of Sciences, Bolshoi pr. V.O. 31, \\ 199004 St. Petersburg, Russia; gplaton@mail.ru \\ 4 Republican Center for Innovative and Technical Creativity, Slavinskogo str. 12, 220086 Minsk, Belarus; \\ centre@rcitt.by \\ 5 St. Petersburg Research Institute of Phthisiopulmonology, Polytechnical str. 32, 194064, St. Petersburg, \\ Russia; vinogradova@spbniif.ru (T.V.); zabol-natal@yandex.ru (N.Z.) \\ * Correspondence: tennikova@mail.ru; Tel.: +7-921-969-1060; Fax: +7-812-363-6722
}

Received: 8 November 2018; Accepted: 18 December 2018; Published: 21 December 2018

\begin{abstract}
The compound 4-thioureidoiminomethylpyridinium perchlorate (perchlozone ${ }^{\odot}$ ) is a novel anti-tuberculosis drug that is active in multiple drug resistance cases, but the compound is hepatotoxic. To decrease the systemic load and to achieve targeting, we encapsulated the drug into poly(lactic acid)-based micro- $(1100 \mathrm{~nm})$ and nanoparticles $(170 \mathrm{~nm})$ that were modified with single-chain camel immunoglobulin G (IgG) for targeting. Both micro- and nanoparticles formed stable suspensions in saline solution at particle concentrations of $10-50 \mathrm{mg} / \mathrm{mL}$. The formulations were injected intraperitoneally and intravenously into the mice with experimental tuberculosis. The survival of control animals was compared to that of mice which were treated with daily oral drug solution, single intraperitoneal administration of drug-loaded particles, and those treated both intravenously and intraperitoneally by drug-loaded particles modified with polyclonal camel IgGs. The distribution of particles in the organs of mice was analyzed with immunofluorescence and liquid chromatography/mass spectrometry. Morphological changes related to tuberculosis and drug toxicity were registered. Phagocytic macrophages internalized particles and transported them to the foci of tuberculosis in inner organs. Nanoparticle-based drug formulations, especially those with IgG, resulted in better survival and lower degree of lung manifestations than the other modes of treatment.
\end{abstract}

Keywords: tuberculosis; polymeric nanoparticles; poly(lactide); 4-thioureidoiminomethylpyridinium perchlorate (perchlozone); macrophage; camel mini-antibodies; opsonization; drug delivery 


\section{Introduction}

Tuberculosis (TB) represents an international health priority and burden, affecting about 10.4 million people annually [1,2]. Human immunodeficiency virus (HIV)/TB co-infection and socioeconomic difficulties make treatment of tuberculosis difficult in many developing countries. Currently, about 1.7 million TB patients die annually, and migration of people tends to spread TB further. Multiple drug resistance of Mycobacterium tuberculosis (MDR-TB) is a major concern in current tuberculosis therapy. According to World Health Organization (WHO) estimates, there are about 490,000 new cases of MDR-TB annually (http:/ / www.who.int/news-room/fact-sheets/detail/ tuberculosis). Thus, effective strategies to overcome this problem are urgently needed [2-4], but the development of new effective drugs is slow.

Recently, a new anti-TB drug, 4-thioureidoiminomethyl pyridinium perchlorate (perchlozone), was introduced and registered in several countries by Pharmsyntez (Irkutsk, Russia). The compound is effective against MDR-TB, but it may cause hepatic toxicity [5-7]. Thus, reduction of toxicity-related drug exposure is needed, while maintaining drug efficacy.

In principle, anti-TB medications could be improved by using carriers that deliver the drug to the infection foci, thereby reducing the required drug doses and potentially decreasing drug toxicity. Previously, anti-microbial compounds were encapsulated into biodegradable micro- and nanoparticles of different polyesters [8-10]. Also, some anti-TB drugs were loaded into poly(lactic-co-glycolic acid) (PLGA)-based microparticles and administered via pulmonary route for treatment of experimental TB in mice [11]. The pulmonary administration of the particles resulted in drug internalization into the alveolar macrophages [12-14]. Likewise, intravenous (i.v.) delivery in PLGA nanoparticles enhanced rifampicin disposition to the lung [15], but the mechanisms of particle transfer to the target tissue remained unclear.

Interestingly, the macrophages and their descendants harbor Mycobacteria and accumulate in the infectious foci [16]. Therefore, targeting of anti-TB compounds to these cells may be an effective strategy to improve therapeutic index of these drugs. Rifampicin and ofloxacine were delivered into alveolar macrophages with inhaled liposomes, hyaluronic acid microspheres, poly(D,L-lactic-co-glycolic) acid and poly(ester-co-amides) [17-20]. The targeted delivery of anti-TB drugs into alveolar macrophages was also achieved by conjugation of phagocyte receptor specific tuftsin peptide or other targeting moieties to the particle surfaces [21-23].

Such drug delivery systems combine features of polymeric particles and intrinsic transfer properties of macrophages, constituting a biohybrid approach [24,25]. Polyester-based micro- and nanoparticles may be useful in this context, because they can entrap drugs and protect the drug inside the phagocytes.

Phagocytosis of perchlozone-loaded particles by macrophages and subsequent localization in the infected foci might result in improved efficacy and safety of the drug [23]. In this study, we loaded perchlozone into the nano- and microparticles of poly(D,L-lactic acid) for targeting the drug via macrophage-mediated chemotaxis into the TB-infected foci in mice. This approach resulted in targeted drug delivery and effective treatment at reduced dosing levels of perchlozone.

\section{Materials and Methods}

\subsection{Materials and Instruments}

All commercially available chemicals were purchased from Fluka (Buchs, Switzerland) and Sigma-Aldrich (Darmstadt, Germany) and used without further purification. The poly(D,L-lactic acid) (PLA, molecular weight $\left(\mathrm{M}_{\mathrm{W}}\right)$ 24,000) for particle preparation was synthesized and characterized according to a previously published procedure [26]. Spin columns (molecular weight cut-off (MWCO) 3000 and 100,000; VIVASCIENCE, Sartorius Group, Göttingen, Germany) were used for dialysis, particle purification and separation. Papain was purchased from Sigma-Aldrich (Germany). Fluorescein isothiocyanate (FITC)-labeled zymosan was taken from Molecular Probes (Thermo Fisher Scientific, Waltham, MA, USA). 
Perchlozone was extracted from commercially available tablets (Pharmasyntez OJSC, Russia) as follows: 2 tablets, containing $400 \mathrm{mg}$ of perchlozone each, were placed into a glass tube, and $5 \mathrm{~mL}$ of distilled water was added. The tube was stirred with a vortex to break down the particles and heated up to $80^{\circ} \mathrm{C}$ for one hour. Then, the deep-yellow solution was separated by filtration and, while cooling down, perchlozone crystallization was observed. The yield was $680 \mathrm{mg}$ of active component. The compound melted at $238-240{ }^{\circ} \mathrm{C}$. The FTIR spectrum of substance was as follows $(\mathrm{KBr}), \mathrm{v}, \mathrm{cm}^{-1}$ : $3420\left(\mathrm{NH}_{2}\right) ; 3310(\mathrm{NH}) ; 1630(\mathrm{C}=\mathrm{N}) ; 1495\left(\mathrm{C}=\mathrm{C}\right.$, ring); $1355(\mathrm{C}-\mathrm{N}) ; 1120(\mathrm{C}=\mathrm{S}) ; 1040\left(\mathrm{ClO}_{4}{ }^{-}\right) .{ }^{1} \mathrm{H}$ NMR spectrum of substance (dimethyl sulfoxide (DMSO- $\left.\left.d_{6}\right)\right), \delta, \mathrm{ppm}: 8.11(1 \mathrm{H},=\mathrm{CH}, s), 8.43(2 \mathrm{H}, \mathrm{H}-3.5$, $d, 3 J=6.5 \mathrm{~Hz}), 8.54\left(1 \mathrm{H}, \mathrm{NH}_{2}, b s\right), 8.66\left(1 \mathrm{H}, \mathrm{NH}_{2}, b s\right), 8.85(2 \mathrm{H}, \mathrm{H}-2,6, d, 3 \mathrm{~J}=6.5 \mathrm{~Hz}), 12.11(1 \mathrm{H}, \mathrm{NH}$, $b s$ ). The ultraviolet (UV) spectrum of substance in water possesses two maxima at 232 and $318 \mathrm{~nm}$. The purity of obtained drug was more than $98 \%$ according to HPLC (Russian Pharmaceutical Standard No000037-241220).

\subsection{Animals}

Animals

Mice. All pathophysiological experiments were organized and maintained on principles of humane care of animals with consent and approval of the bioethical review committee of the Research Institute of Pthisiopulmonology (Statement \#48.1). In total, 152 outbred male albino mice (Rappolovo nursery, St. Petersburg, Russia) weighing $19 \pm 1 \mathrm{~g}$ were used. The eight-week-old [27] outbred mice were chosen to mimic the large genetic variability [28] of human patients. Animals prior to the study were quarantined for 14 days and monitored daily by visual clinical inspection. Only clinically healthy mice with positive body mass dynamics were included in the experiments. They were given a standard diet fortified in protein and vitamins (Furage Ltd., St. Petersburg, Russia), recommended by Russian Health Ministry edict \#1179 for TB-related animal experimentation, plus water ad libitum. The mice were kept at the vivarium of Research Institute of Phthisiopulmonology under standard conditions in full accordance with the "Rules of an establishment, equipment, and maintenance of experimental biological clinics", approved by Russian Federation (RF) State standard R53434-2009. The light conditions were $12 \mathrm{~h}$ light $/ 12 \mathrm{~h}$ darkness, air temperature was maintained between 23 and $25^{\circ} \mathrm{C}$, and relative air humidity was $50-70 \%$. Air exchange was carried out by inflow / outflow ventilation, with daily air sterilization by UV light. The mice were housed in groups of 9-15 animals in polycarbonate cages, with a floor area of at least $56.3 \mathrm{~cm}^{2}$ per animal, covered by pre-disinfected sawdust.

Camel. A donor of camel immunoglobulin (Ig) was a healthy double-humped Bactrian female camel of Kalmyk breed, age three years, body mass $450 \mathrm{~kg}$, from the stable of St. Petersburg State Academy of Veterinary Medicine (SPbSAVM). Feeding was carried out on a complete diet recommended by SPbSAVM, and maintenance was in the stall.

All experiments were carried out in accordance with European Union (EU) Directive 2010/63/EU for animal experimentation, under conditions of humane care of experimental animals, with due euthanasia of survived mice under ether narcosis.

\subsection{Methods}

\subsubsection{Preparation of Perchlozone-Loaded Polymeric Micro- and Nanoparticles}

Microparticles. The double emulsion evaporation method [26] was applied for perchlozone encapsulation into the PLA microparticles. The optimized procedure was as follows: a solution of $300 \mathrm{mg}$ of the drug and $50 \mathrm{mg}$ of lecithin in $1.5 \mathrm{~mL}$ of $0.01 \mathrm{M}$ sodium phosphate buffer, $\mathrm{pH}$ 7.4, was prepared. This solution was emulsified in $15 \mathrm{~mL}$ of organic phase $(10 \mathrm{~mL}$ of dichloromethane, $5 \mathrm{~mL}$ of acetone, $1 \mathrm{~g}$ of PLA, $0.5 \mathrm{~g}$ of lecithin) using an ultrasound homogenizer Sonopuls HD2070 (Bandelin, Berlin, Germany) and magnetic stirrer MR Hei-Mix S (Heidolph, Schwabach, Germany). After 2 min of emulsification, the resulting emulsion was added during $3 \mathrm{~min}$ to $45 \mathrm{~mL}$ of aqueous phase $(1 \mathrm{wt} . \%$ 
poly( $N$-vinylpyrrolidone), $0.5 \mathrm{wt}$ \% sodium dodecyl sulfate, $0.5 \mathrm{wt}$ \% Lutrol F68) under stirring at $1000 \mathrm{rpm}$ and simultaneous sonication to form a double emulsion. Thereafter, the organic solvent was removed from the mixture at reduced pressure with application of Hei-VAP Precision ML/G3B rotary evaporator (Heidolph), one hour at $100 \mathrm{mbar}$ and one hour at $50 \mathrm{mbar}$. The microparticle suspension was centrifuged at $4000 \times g$ for 10 min with application of Sigma 2-16 P (Sigma, Darmstadt, Germany) centrifuge. The separated particles were washed four times with distilled water and resuspended in $0.1 \mathrm{M}$ sodium phosphate-buffered saline, $\mathrm{pH} 7.4$, in which they were stored at $4{ }^{\circ} \mathrm{C}$ until application and resuspended immediately before injection.

Nanoparticles. The nanoparticles were obtained by nanoprecipitation similar to an earlier described procedure [29]. A solution of $100 \mathrm{mg}$ of poly(lactic acid) in $20 \mathrm{~mL}$ of drug solution in acetonitrile was slowly added to $100 \mathrm{~mL}$ of water. The mixture was stirred for two days in an opened flask to eliminate the organic solvent. The particles were purified from free drug via dialysis against $0.1 \mathrm{M}$ phosphate-buffered saline, $\mathrm{pH}$ 7.4, using Vivaspin 20 columns (Sartorius, Göttingen, Germany, MWCO 100,000) and the abovementioned centrifuge.

For biological imaging purposes, both nano- and microparticles were labeled with platinum(II)-coproporphyrin (PtCP). This was done by addition of $50 \mu \mathrm{L}$ of $\mathrm{PtCP}(1 \mathrm{mg} / \mathrm{mL}$ in ethanol) to perchlozone solution just before preparation of particles.

\subsubsection{Particle Characterization}

Particle size, zeta potential, and size distribution. The particle size, zeta potential, and size distribution of freshly prepared particles were determined with dynamic light scattering (DLS) with application of a Zetasizer Nano ZS (Malvern, Enigma Business Park, UK) instrument. The mean size of lyophilized particles was estimated from scanning electron microscope images obtained with a Zeiss Supra 55VP (Basel, Switzerland) instrument and Fiji ImageJ free software (version 1.51j, Laboratory for Optical and Computational Instrumentation (LOCI) at the University of Wisconsin-Madison, Madison, WI, USA, 2017).

Drug loading and encapsulation efficiency. Fourier-transform infrared (FTIR) and X-ray diffraction (XRD) measurements were carried out with a Nicolet 8700 spectrometer (Thermo Fisher Scientific) and D2 Phaser diffractometer (Bruker, Billerica, MA, USA). The samples of particle suspensions $(0.3 \mathrm{~mL})$ were washed three times with distilled water and lyophilized with application of FreeZone 1L Benchtop Freeze Dry System (Labconco, Kanzas City, MO, USA). Dried particles were weighed and dissolved in acetone to evaluate the quantity of perchlozone by measuring the adsorption of the light at $\lambda=380 \mathrm{~nm}$ (molar extinction coefficient-5400) with a UV mini-1240 spectrophotometer (Shimadzu, Tokyo, Japan). The drug loading (mg) and encapsulation efficiency (\%) were calculated as follows:

$$
\begin{aligned}
& \mathrm{DL}=\mathrm{Q}_{\text {particles }} \times \mathrm{m}_{\text {particles }}, \\
& \mathrm{EE}(\%)=\mathrm{DL} \times 100 / \mathrm{DL}_{0},
\end{aligned}
$$

where $Q_{\text {particles }}$ is the quantity of drug entrapped into $1 \mathrm{mg}$ of particles, $\mathrm{m}_{\text {particles }}$ is the total weight of the particles $(\mathrm{mg})$, and $\mathrm{DL}_{0}$ is the theoretical drug loading, calculated as $\mathrm{DL}_{0}=\mathrm{C}_{0} \mathrm{~V}_{0} / \mathrm{m}_{\text {particles}}$, where $\mathrm{C}_{0}$ is initial concentration of the drug solution and $\mathrm{V}_{0}$ is solution volume.

Particle degradation. The degradation of the particles was analyzed by measuring their weight loss as described earlier [26]. Dry particles $(100 \mathrm{mg})$ were placed into Eppendorf ${ }^{\circledR}$ microtubes and mixed with $0.01 \mathrm{M}$ phosphate-buffered saline (PBS, pH 4.5) with $0.1 \%$ SDS and $0.5 \mathrm{mg} / \mathrm{mL}$ papain. This medium was used to mimic lysosomal acidic $\mathrm{pH}$ in the macrophages. At certain time periods, the particles were centrifuged, washed with water, freeze-dried, and weighed with an Ohaus AV313 Adventurer Pro Digital Balance (Moscow, Russia) to evaluate the weight loss of the particles. The weight loss (\%) was calculated as follows:

$$
\operatorname{PWL}(\%)=\left[\left(\mathrm{W}_{0}-\mathrm{W}_{\mathrm{t}}\right) / \mathrm{W}_{0}\right] \times 100 \%,
$$


where $W_{0}$ is the initial weight of the particles, and $W_{t}$ is their weight at certain time $(t)$ in the medium.

Drug release tests. The release study was conducted in a medium that mimics intra-lysosomal conditions in macrophages. The medium contained $0.01 \mathrm{M}$ phosphate-buffered saline ( $\mathrm{pH} 4.5), 0.1 \%$ SDS and $0.5 \mathrm{mg} / \mathrm{mL}$ papain. At defined times during the experiment, the particle suspensions were centrifuged (microparticles $5000 \times g$ for $5 \mathrm{~min}$; nanoparticles $12,000 \times g$ for $5 \mathrm{~min}$ ). Then, $200-\mu \mathrm{L}$ aliquots of supernatant were withdrawn and the concentration of released perchlozone was determined spectrophotometrically (NanoDrop 2000, ThermoFisher Scientific) at $\lambda=318 \mathrm{~nm}$. Cumulative drug release (\%) vs. time curves were generated.

The release data were approximated with application of Higuchi (Equation (4)) and Korsmeyer-Peppas (Equation (5)) release models [30,31]:

$$
\begin{gathered}
\mathrm{Q}=\mathrm{K}_{\mathrm{H}} \mathrm{t}^{1 / 2} . \\
\log \left(\mathrm{M}_{\mathrm{t}} / \mathrm{M}_{\infty}\right)=\log \mathrm{k}+\text { nLogt. }
\end{gathered}
$$

\subsubsection{Camel IgG Fractionation and Attachment to the Particles}

Camel blood was collected from the jugular vein into a hemotransfusion container (Kompoplast 300/300, Syntez OJSC, St. Petersburg, Russia) with sodium citrate. Thereafter, plasma and cells were isolated by centrifugation as described elsewhere [32]. Concentrations of different IgG classes in serum were estimated by their sedimentation at their isoelectric point: $\operatorname{IgA}=6.89 \mathrm{~g} / \mathrm{L} ; \operatorname{IgM}=0.2 \mathrm{~g} / \mathrm{L}$; $\mathrm{IgG}_{1}=10.7 \mathrm{~g} / \mathrm{L} ; \mathrm{IgG}_{2}=0.71 \mathrm{~g} / \mathrm{L}$. Determination of antimycobacterial $\mathrm{Ig}$ in camel blood serum was performed by ELISA method using the kits in "SD Bioline TB WB" (Standard Diagnostics Inc, Borahagal-ro, South Korea) by competition with antimycobacterial standard-calibrated human immunoglobulin samples. The activity was compared to that in uninfected healthy human sera donors and TB patients with various forms of TB (from Biobank of Saint Petersburg Research Institute of Phthisiopulmonology, St. Petersburg, Russia). The approximate level of camel anti-TB IgG (391 \pm 36 units (U)) was estimated to be comparable to that of patient with fresh exacerbation of TB (1040 U), much higher than in an uninfected healthy donor $(<50 \mathrm{U})$ and significantly higher than in non-exacerbated patients with fibro-cavernous (271 U) or infiltrative (209 U) pulmonary TB. A lymphocyte blast transformation test with $20 \mathrm{mg} / \mathrm{mL}$ tuberculin (PAO Farmstandart-Biolek, Kharkov, Ukraine) was positive in $2.2 \%$ of camel lymphocytes. Antimycobacterial activity was preserved in the serum for more than $80 \%$ after a single freeze thawing. We assume that it resulted from natural immunization.

Camel IgGs were isolated from blood plasma by affinity chromatography on a protein A Bio-RAD column (Bio-Scale TM Mini Affi-Prep ${ }^{\circledR P r o t e i n}$ A Cartridge, Bio-Rad Laboratories Inc., Moscow, Russia) in $0.01 \mathrm{M}$ sodium phosphate-buffered saline, $\mathrm{pH}$ 7.4. Then, $1 \%$ acetic acid solution, $\mathrm{pH} 3.0$, was applied for IgG detachment and dry Tris buffer was used for its neutralization.

The surface of both micro- and nanoparticles was carboxylated by treatment with $0.01 \mathrm{M}$ sodium hydroxide for $30 \mathrm{~min}$. The carboxylic groups were then activated with excess of 1-hydroxybenzothriazole/1-ethyl-3-(3-dimethylaminopropyl)carbodiimide mixture in $0.01 \mathrm{M}$ 2-(N-morpholino)ethanesulfonic acid (MES) buffer solution (pH 5.5). The camel IgG was coupled to the particles in $0.01 \mathrm{M}$ sodium borate buffer at $\mathrm{pH} 8.8$. The quantity of coupled IgG $(5 \mu \mathrm{g} / \mathrm{mg}$ of particles) was estimated photometrically by analyzing supernatant solution at $280 \mathrm{~nm}$.

\subsubsection{Ex Vivo Determination of Particle Phagocytosis by Peritoneal Macrophages}

The phagocytosis of cells in the fluid was proved with FITC-labeled zymosan according to a previously published procedure [33]. The morphology of phagocytes was estimated with optical microscopy, and they had all peculiarities of macrophages. 
The micro- and nanoparticles were prepared as described above and covalently modified by Cy3-NHS-labeled bovine serum albumin (BSA) and camel IgG. The Cy3 was introduced for particle visualization by confocal laser microscopy.

In these experiments, 25 mice were used as five groups with five animals in each: (1) control group; (2) group treated with PLA-BSA-Cy3 microparticles; (3) group treated with PLA-BSA-Cy3 nanoparticles; (4) group treated with PLA-camel IgG-Cy3 microparticles; (5) group treated with PLA-camel IgG-Cy3 nanoparticles. Particle suspensions $(0.5 \mathrm{~mL}, 10 \mathrm{wt} . \%)$ in saline were injected intraperitoneally (groups 2-5). After $20 \mathrm{~min}$, the animals were euthanized and $5 \mathrm{~mL}$ of saline solution was administered intraperitoneally (i.p.) to wash out the remaining particles. Fluid (2.5-3.0 mL) was withdrawn from the peritoneum of each mouse, and $1 \mathrm{~mL}$ of the retrieved liquid was placed on the coverslips in Petri dishes and incubated for 1 hour at $5 \% \mathrm{CO}_{2}$ and $37^{\circ} \mathrm{C}$. Then, the dish content was washed with saline solution (at $30^{\circ} \mathrm{C}$ ) and fixed with $4 \%$ paraformaldehyde for $40 \mathrm{~min}$ in the darkness. Then, the samples were washed with saline three times for $20 \mathrm{~min}$ and stored in the freezer $\left(4^{\circ} \mathrm{C}\right)$ until analyzed [34].

The samples were stained in the dark with 4',6-diamidino-2-phenylindole (DAPI; $0.36 \mu \mathrm{M}$ in PBS) for $5 \mathrm{~min}$ at room temperature $\left(25^{\circ} \mathrm{C}\right)$ and washed twice with $0.01 \mathrm{M}$ PBS, pH 7.4. The coverslips were attached to the microscope slides with Dako mounting medium (Agilent Technologies, Santa Clara, CA, USA) equipped with Plan-Apochromat $20 \times / 0.8 \mathrm{M} 27$ and C-Apochromat $40 \times / 1.20 \mathrm{~W}$ CorrUV-VIS-IRM27 objectives. For excitation of Cy3 and DAPI fluorescence, 561-nm and 405-nm lasers were applied, respectively. The fluorescence of $\mathrm{Cy} 3$ was detected with a 570-613-nm filter, and DAPI was imaged with a 420-480-nm filter. The images in transmitted light were obtained using a differential interference contrast technique. The images were converted into JPEG files by application of software supplemented to the confocal microscope.

The phagocytosis efficacy (\%) was calculated as the percentage of the cells with particles compared to the total number of cells.

\subsubsection{Detection of Particles in Different Organs}

To check the distribution of particles, we studied the fluorescence of encapsulated PtCP in the tissues of different organs. Laparotomy was performed to mice under ether narcosis on the first, second, and seventh day after i.p. injection of particles. Fluorescence of inner organs from perished or euthanized mice was registered. Paraffin-embedded tissue slices were studied using a laser fluorometric scanner Diagem (Immunoscreen Inc., Moscow, Russia) [35] at excitation length $350 \mathrm{~nm}$ and detection at $662 \mathrm{~nm}$ with a delay of $20 \mu \mathrm{s}$. Quantitative estimation of fluorescence intensity was performed by integration of a signal over total slice square. To visualize the PtCP-loaded particles fluorescence in the lung, the fluoromicroscope attachment (Immunoscreen Inc.) was used.

\subsubsection{Investigation of Perchlozone Distribution}

Perchlozone analysis. Liquid chromatography/mass spectrometry (LC-MS) analyses were performed with a Shimadzu 8030 (Kyoto, Japan) chromatograph, supplied with degasser, binary pump, autosampler, thermostate, multi-wavelength UV-visible light (Vis) detector and MS-detector QQQ. The separation was carried out with application of a Phenomenex column (Luna C18 $5 \mu \mathrm{m}$, $150 \times 2.1 \mathrm{~mm})$. As the mobile phase in liquid chromatography, we used a mixture of acetonitrile $(\mathrm{ACN})$ and $0.1 \%$ trifluoroacetic acid (TFA; $85: 15)(\mathrm{pH}=2.6)$. The flow rate was $1 \mathrm{~mL} / \mathrm{min}$ and temperature was $40^{\circ} \mathrm{C}$. The injected sample volume was $2 \mu \mathrm{L}$. Ionization in mass spectrometry was carried out by means of electrospray at atmospheric pressure: voltage on the capillary-1900 V, drying nitrogen velocity $-13.3 \mathrm{~mL} / \mathrm{min}$, spraying nitrogen velocity $-2.7 \mathrm{~mL} / \mathrm{min}$, and drying gas temperature $-250^{\circ} \mathrm{C}$. The detection was carried out in a positive mode of analysis by the multiple reaction monitoring (MRM) method by taking the $183.2 \mathrm{~m} / \mathrm{z}$ peak as a molecular ion. Transitions were $183.2-142.2$ at $20 \mathrm{eV}$ and 183.2-113.2 at $20 \mathrm{eV}$. The retention time of the perchlozone was $1.39 \mathrm{~min}$ and total analysis time was five minutes. 
Calibration curve. Perchlozone was isolated from a powder substance. A weighed portion of the powder (it was assumed that the perchlozone content was as in tablet, equal to $67 \%$ ) of $5 \mathrm{mg}$ was dissolved in $1 \mathrm{~mL}$ of $\mathrm{MeOH}$, stirred with a vortex, and placed into an ultrasonic bath for $15 \mathrm{~min}$. Then, the suspension was centrifuged for $30 \mathrm{~min}$ at $20^{\circ} \mathrm{C}$ at a speed of $13,000 \mathrm{rpm}$. Then, the solution was filtered through a filter having a pore diameter of $0.22 \mu \mathrm{m}$, and the solution was dried in a vacuum at $45^{\circ} \mathrm{C}$. The precipitate was stored at $-70{ }^{\circ} \mathrm{C}$ before analysis, dissolved in $110 \mu \mathrm{L}$ of ACN:0.1\% TFA, $\mathrm{pH}=2.6$ at a ratio of 10:1. Next, standard solutions were prepared by dissolving the initial solution by eluent. To calibrate the instrument and validate the procedure, solutions with a concentration of 0.07 , $0.33,0.67,3.33$, and $13.33 \mu \mathrm{g} / \mathrm{mL}$ were used. The calibration chart had values of $R=0.998$, and relative standard deviation $(\mathrm{RSD} \%)=27 \%$.

Slice analysis. One-third of the slice was mechanically detached from the paraffin and transferred to the Eppendorf tube. Then, $1 \mathrm{~mL}$ of $80 \%$ methanol was added, and the sample was placed into a homogenizer and heated to $70{ }^{\circ} \mathrm{C}$ for $45 \mathrm{~min}$. Then, the tube was transferred to the ice for $10 \mathrm{~min}$ and centrifuged at $4{ }^{\circ} \mathrm{C}$ at $13,000 \mathrm{rpm}$. The supernatant was taken out and lyophilized. The dried powder was dissolved in $100 \mu \mathrm{L}$ of eluent and mixed with a vortex, centrifuged (10 min at 13,000 rpm), and diluted 100-fold with eluent. The solution was filtered and transferred to the vial for detection of perchlozone concentration using LC-MS.

\subsubsection{In Vivo Experiments with Tuberculosis Mice}

The mice were separated into seven groups (Table 1). The remaining non-infected mice were used for model experiments to explore dynamics of particle distribution after single i.p. injection.

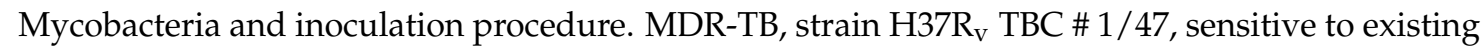
anti-TB drugs, was procured from a culture collection of the Institute of Hygiene and Epidemiology (Prague, Czech Republic). It was maintained on Lőwenstein-Jensen medium through routine bimonthly passage. To inoculate infection, mycobacterial growth of the second generation (21 days old) maintained on solid Lôwenstein-Jensen medium was harvested (according to the guide on the holding of preclinical research of drugs, Ministry of Healthcare and Social Development of the Russian Federation, similar to that published in Reference [36]). It was weighed, and a $5 \mathrm{mg} / \mathrm{mL}$ suspension was prepared by homogenizing the culture in sterile saline with glass beads as described below. The bacterial mass collected from the dense medium was placed in a dry sterile glass test tube with 8-10 glass beads with a diameter of $3 \mathrm{~mm}$, and triturated with a vortex shaker for 15-20 s. Then, three drops of saline were added and triturated further. Then, $5-6 \mathrm{~mL}$ of saline was added and the stirring procedure was repeated. The suspension was then transferred to a centrifuge tube and the clamps were precipitated at $1000 \mathrm{rpm}$ for $10 \mathrm{~min}$. The upper part of the supernatant was carefully withdrawn, avoiding capture of the clamps in the lower layers, and transferred to a polystyrene tube for turbidity measurements. The suspension was adjusted to 1.5 units according to McFarland $5 \times 10^{8}$ cells $/ \mathrm{mL}$ using a DENSI-LA-METER II (Erba Lachema s.r.o., Brno, Czech Republic) densitometer. Then, the resulting suspension was diluted with saline to the desired concentration for infection. One milligram of culture was equivalent to about $10^{6}$ colony-forming units (CFU) as determined from a sample of suspension plated to confirm the number of viable bacilli.

Mice were infected i.v. by injection of about $10^{6} \mathrm{CFU}$ or $0.2 \mathrm{~mL}$ of the above suspension via the lateral caudal vein. The mice were weighed and clinically examined daily. Every second day, beginning from day 7 after inoculation, a random mouse from the untreated $(\mathbf{U})$ group was euthanized and investigated on autopsy in order to reveal macroscopic foci of infection. Starting from day 7 after inoculation, multiple submiliary $(<1 \mathrm{~mm}$ in diameter) and few miliary foci of inflammation were observed in inner organs, mostly in the lungs and liver. The mice developed severe infection by 11 to 13 days and lost weight during TB progression. The animals in the control group were given i.v. saline. 
Table 1. The description of groups of mice involved in the experiment. Abbreviations: p/o—per os; i.p.-intraperitoneally; i.v.—intravenously; PCZ-perchlozone; IgG-immunoglobulin; TB-tuberculosis.

\begin{tabular}{|c|c|c|c|c|c|}
\hline Abbreviation & $\begin{array}{l}\text { Description of Animals/Periodicity } \\
\text { of Treatment/Type of Particles }\end{array}$ & $\begin{array}{c}\text { Means of } \\
\text { Treatment }\end{array}$ & $\begin{array}{c}\text { Suspension } \\
\text { Volume/Concentration/Medium }\end{array}$ & Dose & $\begin{array}{c}\text { Number of } \\
\text { Animals }\end{array}$ \\
\hline $\mathbf{N}$-non-treated & $\begin{array}{l}\text { healthy controls/no treatment/no } \\
\text { particles }\end{array}$ & none & none & none & 15 \\
\hline U-untreated & TB-infected mice/daily/no particles & $\mathrm{p} / \mathrm{o}$ & $0.2 \mathrm{~mL}$ of pure saline & none & 33 \\
\hline $\begin{array}{l}\text { PCZ per os-perchlozone } \\
\text { per os }\end{array}$ & TB-infected mice/daily/no particles & $\mathrm{p} / \mathrm{o}$ & $\begin{array}{l}0.5 \mathrm{~mL} \text { of drug solution } \\
0.6 \mathrm{mg} / \mathrm{mL} \text { in saline }\end{array}$ & $\begin{array}{l}\text { single dose }=15 \mathrm{mg} / \mathrm{kg} \text { total } \\
\text { dose for survived } \\
\text { mice }=600 \mathrm{mg} / \mathrm{kg}\end{array}$ & 15 \\
\hline $\begin{array}{l}\text { MPs i.p.-microparticles } \\
\text { introperitoneally }\end{array}$ & $\begin{array}{c}\text { TB-infected } \\
\text { mice/once/microparticles }\end{array}$ & i.p. & $0.5 \mathrm{~mL} / 10 \mathrm{wt} . \% /$ saline & none & 11 \\
\hline $\begin{array}{c}\text { MPs + PCZ } \\
\text { i.p.-microparticles }+ \\
\text { perchlozone intraperitoneally }\end{array}$ & $\begin{array}{c}\text { TB-infected } \\
\text { mice/once/microparticles }\end{array}$ & i.p. & $0.5 \mathrm{~mL} / 10 \mathrm{wt} . \% /$ saline & $\begin{array}{l}\text { single dose and total } \\
\text { dose }=41 \mathrm{mg} / \mathrm{kg}\end{array}$ & 15 \\
\hline $\begin{array}{c}\text { MPs-IgG + PCZ } \\
\text { i.p.-microparticles modified } \\
\text { with IgG + perchlozone } \\
\text { intraperitoneally }\end{array}$ & $\begin{array}{c}\text { TB-infected } \\
\text { mice/once/microparticles modified } \\
\text { with camel IgG }\end{array}$ & i.p. & $0.5 \mathrm{~mL} / 10$ wt. $\% /$ saline & $\begin{array}{l}\text { single and total dose } \\
\begin{array}{c}\text { drug }=41 \mathrm{mg} / \mathrm{kg} \\
\operatorname{IgG}=3 \mathrm{mg} / \mathrm{kg}\end{array}\end{array}$ & 11 \\
\hline $\begin{array}{c}\text { [NPs-IgG + PCZ] i.v. + } \\
\text { [MPs-IgG + PCZ] } \\
\text { i.p.--nanoparticles loaded with } \\
\text { perchlozone and modified with } \\
\text { camel IgG intravenously and } \\
\text { microparticles loaded with } \\
\text { perchlozone and modified with } \\
\text { camel IgG intraperitoneally }\end{array}$ & $\begin{array}{l}\text { TB-infected mice/once intravenously } \\
\text { by nanoparticles loaded with } \\
\text { perchlozone and modified with } \\
\text { camel IgG intravenously and } 1 \text { week } \\
\text { later microparticles loaded with } \\
\text { perchlozone and modified with } \\
\text { camel IgG intraperitoneally/nano- } \\
\text { and microparticles }\end{array}$ & i.v. + i.p. & $\begin{array}{c}\text { i.v.: } \\
0.2 \mathrm{~mL} / 10 \text { wt. } \% / \text { saline } \\
\text { i.p.: } \\
0.5 \mathrm{~mL} / 10 \text { wt. } \% / \text { saline }\end{array}$ & $\begin{array}{l}\text { drug dose: } \\
\mathrm{v} .=3 \mathrm{mg} / \mathrm{kg}, \text { i.p. }=41 \mathrm{mg} / \mathrm{kg} . \\
\text { otal dose of drug }=44 \mathrm{mg} / \mathrm{kg} \\
\text { immobilized } \mathrm{IgG} \text { doses: } \\
\text { v. }=2 \mathrm{mg} / \mathrm{kg}, \text { i.p. }=3 \mathrm{mg} / \mathrm{kg} \\
\text { Total dose of } \operatorname{IgG}=5 \mathrm{mg} / \mathrm{kg}\end{array}$ & 9 \\
\hline
\end{tabular}


Treatment and survival analysis. As listed above, treatment in all infected groups, except group $\mathrm{U}$, started from the 13th day after inoculation. Every day, the dead animals were autopsied with visual evaluation of the degree of macroscopic lung damage (DLD) [37-39], labeled and placed in 10\% buffered formalin solution. All mice were maintained until death of $97 \%$ animals in control U group. All animals that survived to the 54th day of experiment were euthanized and explored for severity of lung involvement, lung weight, and index of lung bacilli insemination $(\operatorname{lgCFU})$, calculated as

$$
\operatorname{lgCFU}=\lg \left(\mathrm{CFU} \times \mathrm{L}_{\mathrm{m}} \times 10^{6}\right),
$$

where $\mathrm{L}_{m}$ is lung mass in grams. The colony-forming unit (CFU) was determined as follows: the lungs were aseptically removed and weighed, and $0.1 \mathrm{~g}$ of each lung was separately pooled and homogenized in sterile saline. Serial dilutions of the homogenates were prepared in sterile saline. The fifth dilution was inoculated onto duplicate set of slants of Lőwenstein-Jensen medium, and incubated for 21 to 28 days at $37^{\circ} \mathrm{C}$. After appearance of visible growth, the isolated colonies were counted [40]. Survival curves in all groups were plotted and compared by statistical methods described below.

Pathomorphological studies. The samples of lung, liver, spleen, and brain were taken from mice of all groups. The samples were fixed in $10 \%$ buffered formalin. Paraffin slices were prepared and stained as described above. Optical microscopy of sections was performed with a Karl Zeiss Primo Star microscope and a Leica DC fluorescence microscope (Leica Microsystems GmbH, Wetzlar, Germany).

\subsubsection{Statistical Analysis}

The results are expressed as means \pm standard deviation (SD). The intergroup variation was measured by one-way analysis of variance (ANOVA) followed by Fisher's least significant difference test. The survival curves in pathophysiological experiments were analyzed by comparing multiple samples with log-rank Mantel-Cox test and Cox' F-criterion [41]. Statistical significance of the results everywhere was calculated as $p<0.05$ or better.

\section{Results}

\subsection{Particle Preparation and PCZ Loading}

Perchlozone encapsulation into PLA-based micro- and nanoparticles was performed using double emulsion evaporation and nanoprecipitation methods, respectively. The mean hydrodynamic diameter of microparticles was $1100 \mathrm{~nm}$ and the particle size distribution was relatively broad (Figure 1). The nanoparticles showed mean hydrodynamic diameter of $170 \mathrm{~nm}$ (Figure 1). The mean sizes of dry particles (scanning electron microscopy images) and particle suspensions (dynamic light scattering) matched with each other (Figure 1). The mean $\zeta$-potential values of microparticles and nanoparticles with perchlozone were slightly negative. This was caused by the terminal carboxylic groups of PLA on the surface of the particles.

Perchlozone was successfully loaded into nano- and microparticles. Drug entrapment levels increased from 8 to $16 \mathrm{mg} / \mathrm{g}$ of particles by applying lecithin as stabilizer. Lecithin has a low hydrophile/lipophile balance (HLB) number and it formed fine water-in-oil emulsion during the particle preparation process. Overall, the perchlozone encapsulation efficacy (relative to the theoretical value) was $11 \%$ and $32 \%$ for microparticles and nanoparticles, respectively. The amount of drug entrapped was $16 \mathrm{mg} / \mathrm{g}$ of microparticles and $50 \mathrm{mg} / \mathrm{g}$ of nanoparticles.

Camel IgG was successfully attached to both micro- and nanoparticles. The amounts of bound protein were 1.2 and $2.0 \mathrm{mg} / \mathrm{g}$ of micro- and nanoparticles, respectively.

The IR spectra of the microparticles and nanoparticles loaded with perchlozone showed strong $\mathrm{C}=\mathrm{S}$ bond vibration band at $1370 \mathrm{~cm}^{-1}$. This reflected the presence of perchlozone in the particles. The study of particles with XRD did not reveal any perchlozone crystalline phase, but an amorphous halo of the PLA was detected. 


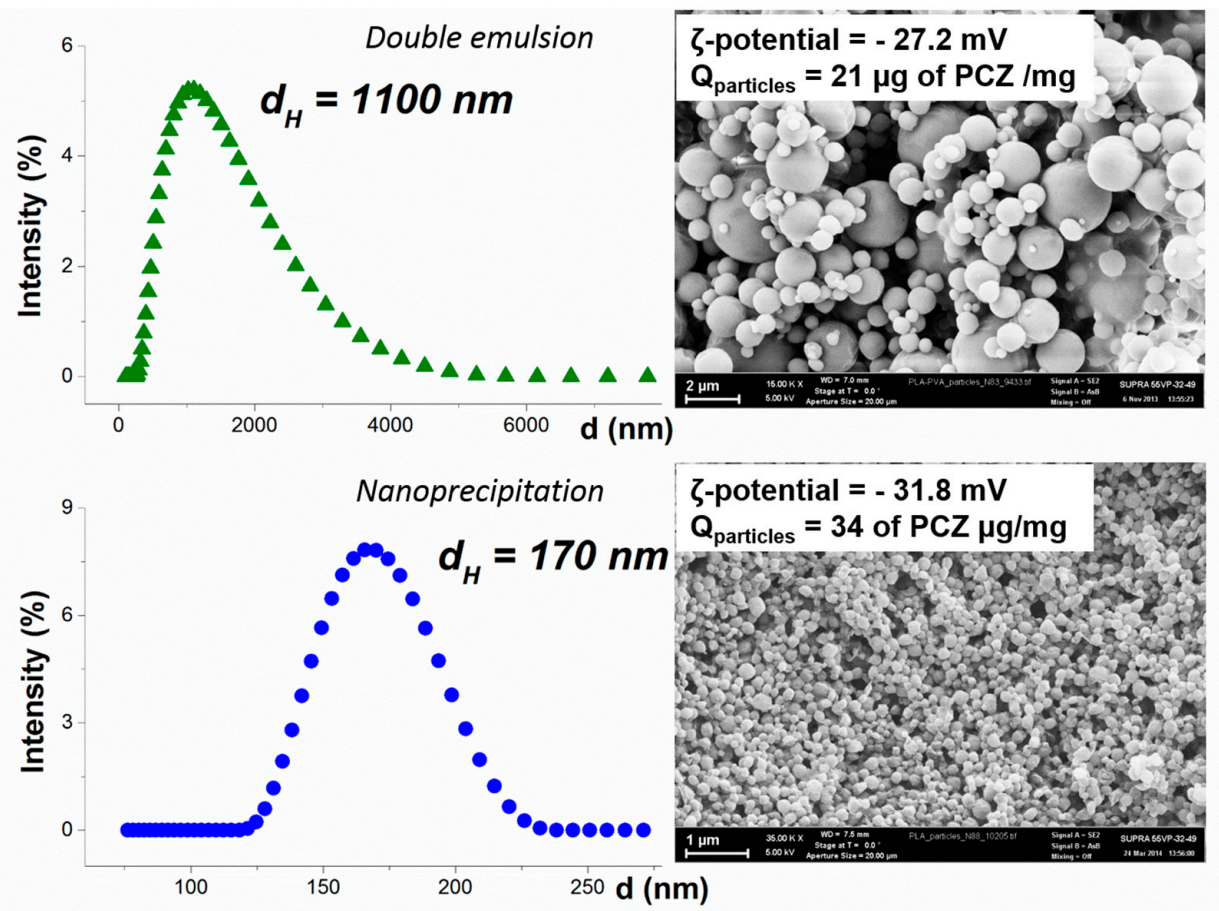

Figure 1. Characteristics of perchlozone loaded poly(lactic acid) (PLA) particles used for treatment of animals. Above: microparticles obtained by double emulsion method; below: nanoparticles obtained by nanoprecipitation.

\subsection{In Vitro Particle Degradation and Perchlozone Release}

Degradation of the particles was studied in vitro in 0.01 M PBS ( $\mathrm{pH} 4.5)$ with $0.1 \%$ SDS and $0.5 \mathrm{mg} / \mathrm{mL}$ papain. The weight loss of the particles over 50 days was $75 \%$ and $88 \%$ for microparticles and nanoparticles, respectively (Figure 2A). The more rapid degradation of nanoparticles may be due to the greater surface area of the nanoparticles.

Perchlozone release studies revealed a burst release of about $30 \%$ of the encapsulated drug (Figure 2B). The perchlozone release rate was faster from nanoparticles than from microparticles. Fitting of perchlozone release data using the Korsmeyer-Peppas model revealed that the main mechanism of drug release was diffusion (see Figure S1). This is in line with the fact that perchlozone release from the particles was faster than the degradation of the particles.

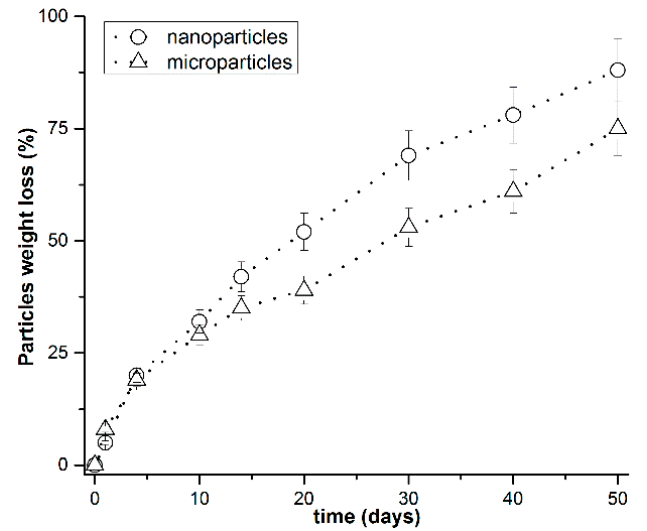

(A)

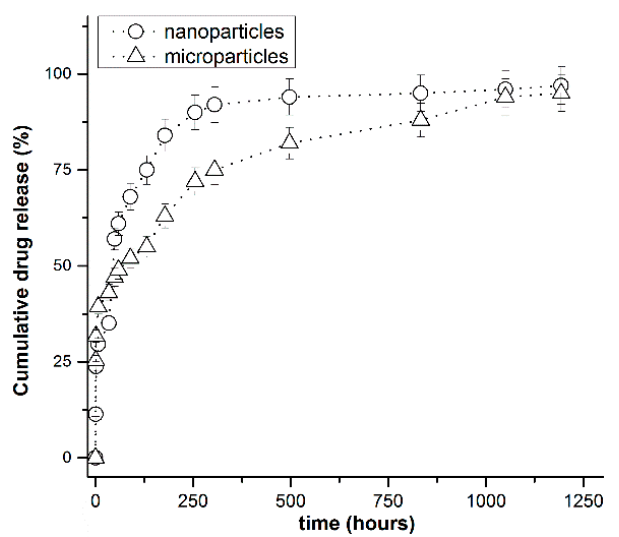

(B)

Figure 2. Kinetic curves of PLA particle weight loss (A) and perchlozone release (B). Conditions: $0.01 \mathrm{M}$ phosphate-buffered saline (PBS), pH 4.5 containing $0.1 \%$ SDS and $0.5 \mathrm{mg} / \mathrm{mL}$ papain. The standard deviation is given as error bars. 


\subsection{Particle Phagocytosis In Vivo}

Both PLA-based micro- and nanoparticles were modified with two fluorescent protein/Cy3 conjugates: BSA-Cy3 and camel IgG-Cy3. The labeled particles were injected intraperitoneally into the mice and the peritoneal fluid was then taken and analyzed.

The labeled particles were found mostly inside of the phagocytic cells (Figure 3). Analysis of the slides with confocal microscopy showed greater cellular uptake of IgG-Cy3-modified microparticles (Figure 3B) than BSA-Cy3-modified microparticles (Figure 3A). The phagocytic delivery was evaluated by analyzing the fraction of macrophages with phagocytosed micro- and nanoparticles. The data revealed that (1) attachment of IgG enhanced phagocytosis of both micro- and nanoparticles and (2) the phagocytosis of IgG-containing microparticles was more effective than phagocytosis of nanoparticles (Figure 4). Overall, it could be concluded that internalization of all types of particles in the mouse peritoneum was quite effective.

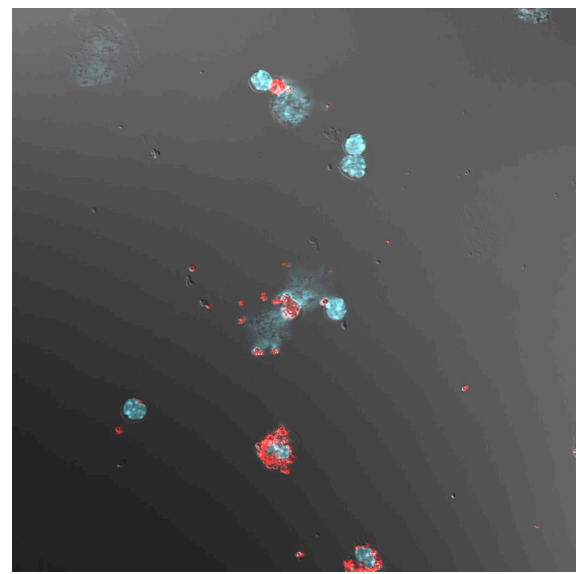

(A)

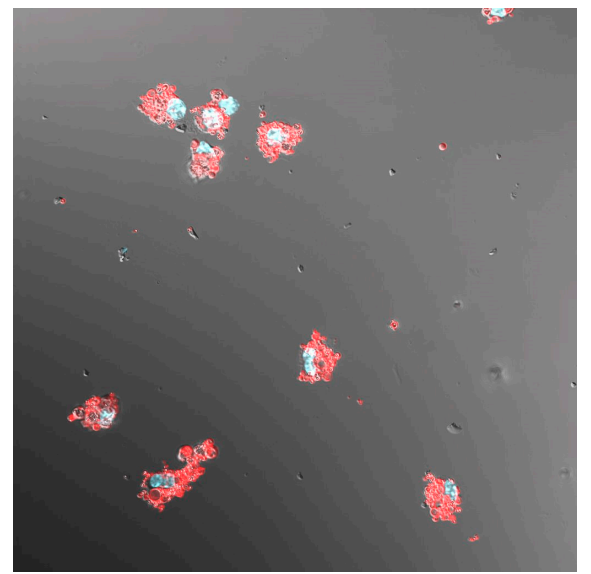

(B)

Figure 3. Confocal microscopy images of 4',6-diamidino-2-phenylindole (DAPI)-stained macrophages, derived from the peritoneal cavity of the mice, with (A) PLA microparticles modified by bovine serum albumin (BSA)-Cy3; (B): PLA microparticles modified by camel immunoglobulin G (IgG)-Cy3.

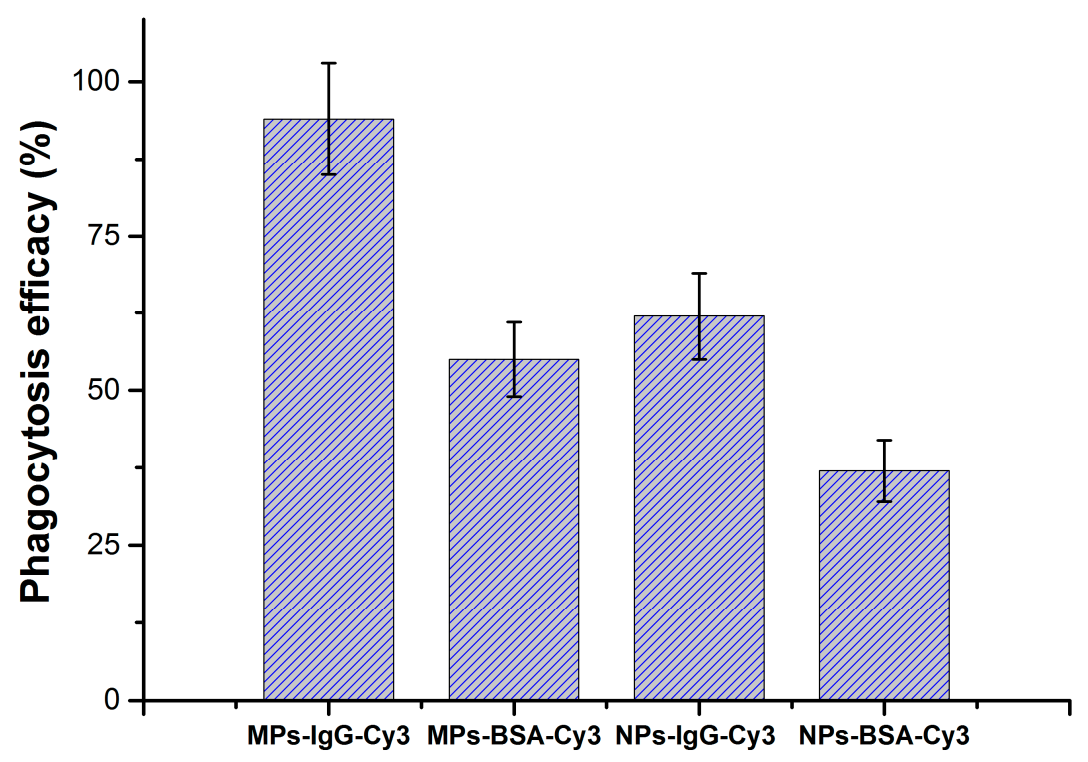

Figure 4. The effect of PLA particle size and IgG attachment on the percentage of macrophages derived from the peritoneal cavity of mice with internalized particles compared to the total number of macrophages. 


\subsection{Survival Data and Severity of TB Involvement among Survived Mice}

Mean longevity (Figure 5) in the untreated mouse group (U) was $23.7 \pm 1.3$ days and the survival time of the mice with oral perchlozone treatment was $28.5 \pm 3.5$ days. The survival time of animals treated with unloaded particles $(22.4 \pm 2.0$ days $)$ did not differ from the controls. However, single i.p. injection of perchlozone-loaded microparticles extended survival of animals to $30.7 \pm 3.6$ days $(p<0.05$, compared with $\mathbf{U})$. Single i.p. injection of perchlozone loaded and IgG-opsonized microparticles resulted even longer survival time (33.2 \pm 3.0 days; $p<0.05$, compared with $U)$.

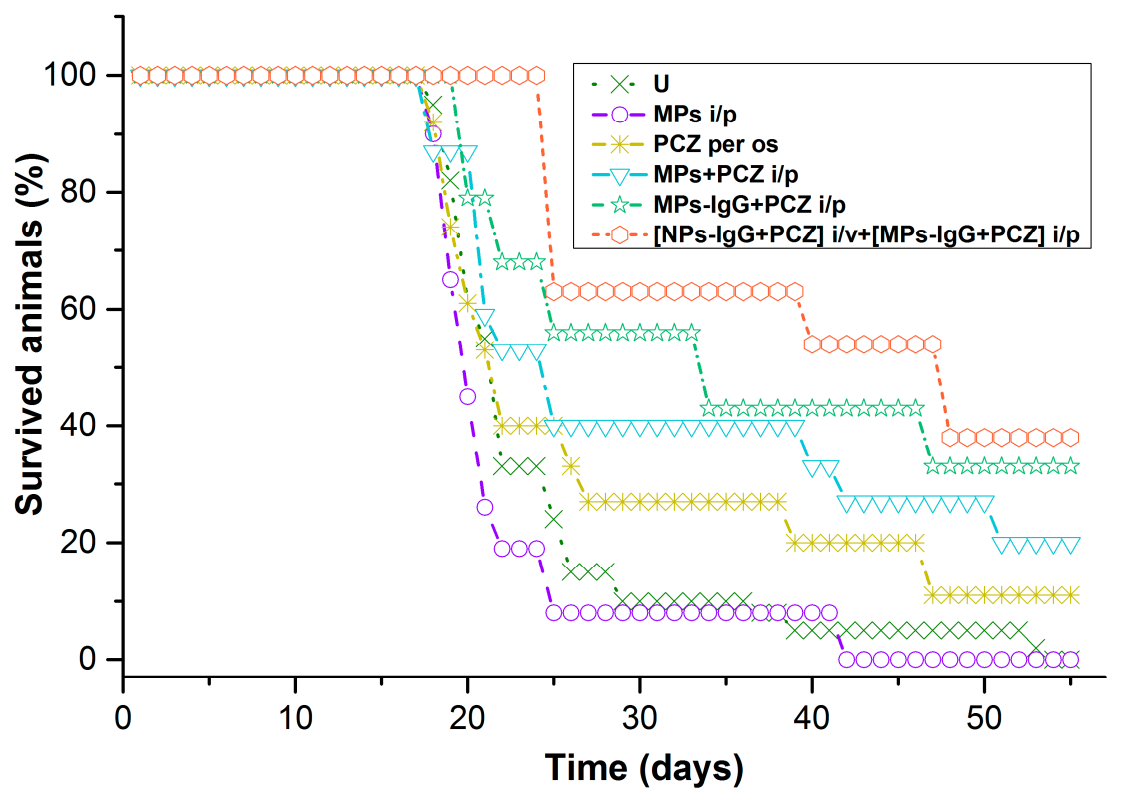

Figure 5. Survival of the multidrug resistance tuberculosis (MDR-TB)-infected mice after various treatments. Time " 0 " is the starting point of MDR-TB inoculation; the treatment started on the 13th day of infection. Group U: untreated control animals; saline was given orally daily. Group MPs i.p.: mice were treated with drug-free PLA microparticles once intraperitoneally (i.p.) Group PCZ per os: perchlozone was given daily orally as saline solution. Group MPs + PCZ i.p.: mice were treated with perchlozone loaded PLA microparticles, once i/p; Group MPs-IgG + PCZ i/p: the mice were injected once i.p. with perchlozone loaded PLA microparticles with camel IgG. Group [NPs-IgG + PCZ] i.v. + [MPs-IgG + PCZ] i.p.: mice were treated with perchlozone loaded and IgG covered PLA nanoparticles, once i.v. and, after one week, an additional i.p. injection of perchlozone-loaded PLA microparticles was delivered. For peculiarities and doses, see Table 1.

The longest mean survival time of $37.6 \pm 5.0$ days was seen (Figure 5) in mice with combined treatment including i.v. injection of IgG-opsonized nanoparticles with entrapped perchlozone and i.p. injection of IgG-opsonized microparticles, also with entrapped perchlozone. It should be noted here that total doses of perchlozone were much lower in the particle injection groups (44 mg/ $\mathrm{kg}$ ) than during the daily oral dosing group $(600 \mathrm{mg} / \mathrm{kg})$. For detailed dosage description, see Table 1.

Survival curves were analyzed with a log-rank Mantel-Cox test. Extended survival of mice was seen in the group that received perchlozone as intravenous nanoparticle injections and intraperitoneal injection of perchlozone-loaded microparticles one week later ([NPs-IgG + PCZ] i.v. + [MPs-IgG + PCZ] i.p.) (Figure 6). This group showed significantly greater longevity of mice compared with untreated animals (Figure 6A), and those treated with oral perchlozone treatment (Figure 6B). 

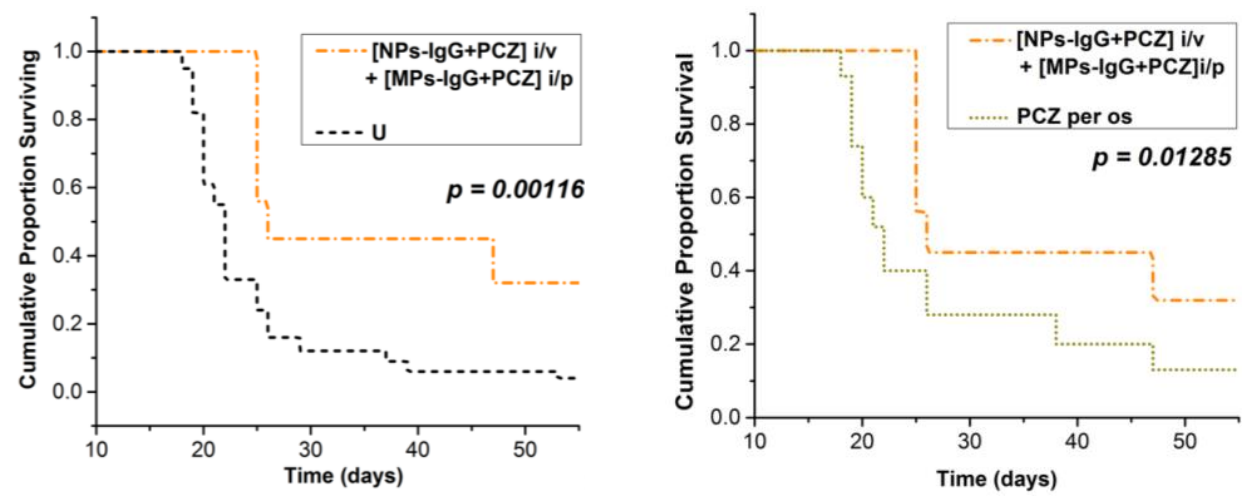

Figure 6. Log-rank Mantel-Cox survival curves comparison: (A) [NPs-IgG + PCZ] i.v. + [MPs-IgG + PCZ] i.p. group versus U group; (B) [NPs-IgG + PCZ] i.v. + [MPs-IgG + PCZ] i.p. group versus PCZ per os group (see Table 1 for group descriptions).

Survival rate in the PCZ per os group was higher than in the untreated control group (U). However, comparison of lung damage degree, lung weight, and lgCFU insemination indexes of all animals survived which until the 54th day of experiment showed less damage and tendency to less insemination in the joint cohort of survived animals from MPs + PCZ i.p. versus those of the PCZ per os group (Table 2). One survived animal from [NPs-IgG + PCZ] i.v. + [MPs-IgG + PCZ] i.p. group even gave a negative result in the CFU inoculation test.

Table 2. Degree of lung involvement and insemination in survived mice. Abbreviations: $\mathrm{L}_{\mathrm{m}}-\mathrm{mass}$ of the lung; DLD—degree of macroscopic drug damage (see Section 2); CFU—colony-forming unit; lgCFU—index of lung bacilli insemination.

\begin{tabular}{ccc}
\hline \multirow{2}{*}{ Parameter } & \multicolumn{2}{c}{ Group } \\
\cline { 2 - 3 } & PCZ per os & MPs + PCZ i/p \\
\hline L $_{\mathrm{m}}, \mathrm{g}$ & $0.59 \pm 0.06$ & $0.41 \pm 0.05$ \\
$\mathrm{~L}_{\mathrm{m}}$ \% of body mass & $1.97 \pm 0.20$ & $1.33 \pm 0.20$ \\
DLD & $3.36 \pm 0.27$ & $2.50 \pm 0.17$ \\
$\lg$ CFU & $2.08 \pm 0.60$ & $1.21 \pm 0.44$ \\
\hline
\end{tabular}

\subsection{Concentration of Encapsulated Fluorescent Label and Perchlozone in the Organs of Experimental Mice}

The accumulation of particles in the lung was imaged by detection of PtCP label luminescence, which was encapsulated into the particles together with perchlozone (Figure 7). The luminescence of encapsulated PtCP was visualized both on the surface (Figure 7A) and within the slices (Figure 7B) of the derived lung of mouse from the MPs + PCZ i.p. group. The greater luminescence was seen after treatment of MDR-TB-infected lung (Figure 7C1) as compared to untreated lung (Figure 7C2) and luminescence in the liver and brain (Figure 7C3 and C4, correspondingly). Quantification of $\mathrm{PtCP}$ concentration in different organs of the mice was also performed (Table 3). The results showed significant particle accumulation within foci of infection in the lung and liver in the animals treated with microparticles. Traces of signal at slices of untreated mice are commonly caused by presence of natural Zn-containing proteins [42]. Greater particle accumulation was detected in the case of microparticles with camel IgG (Table 3). Pathomorphologically, the areas of high signal contained foci of TB inflammation with mononuclear cell infiltration (see Table 2). 

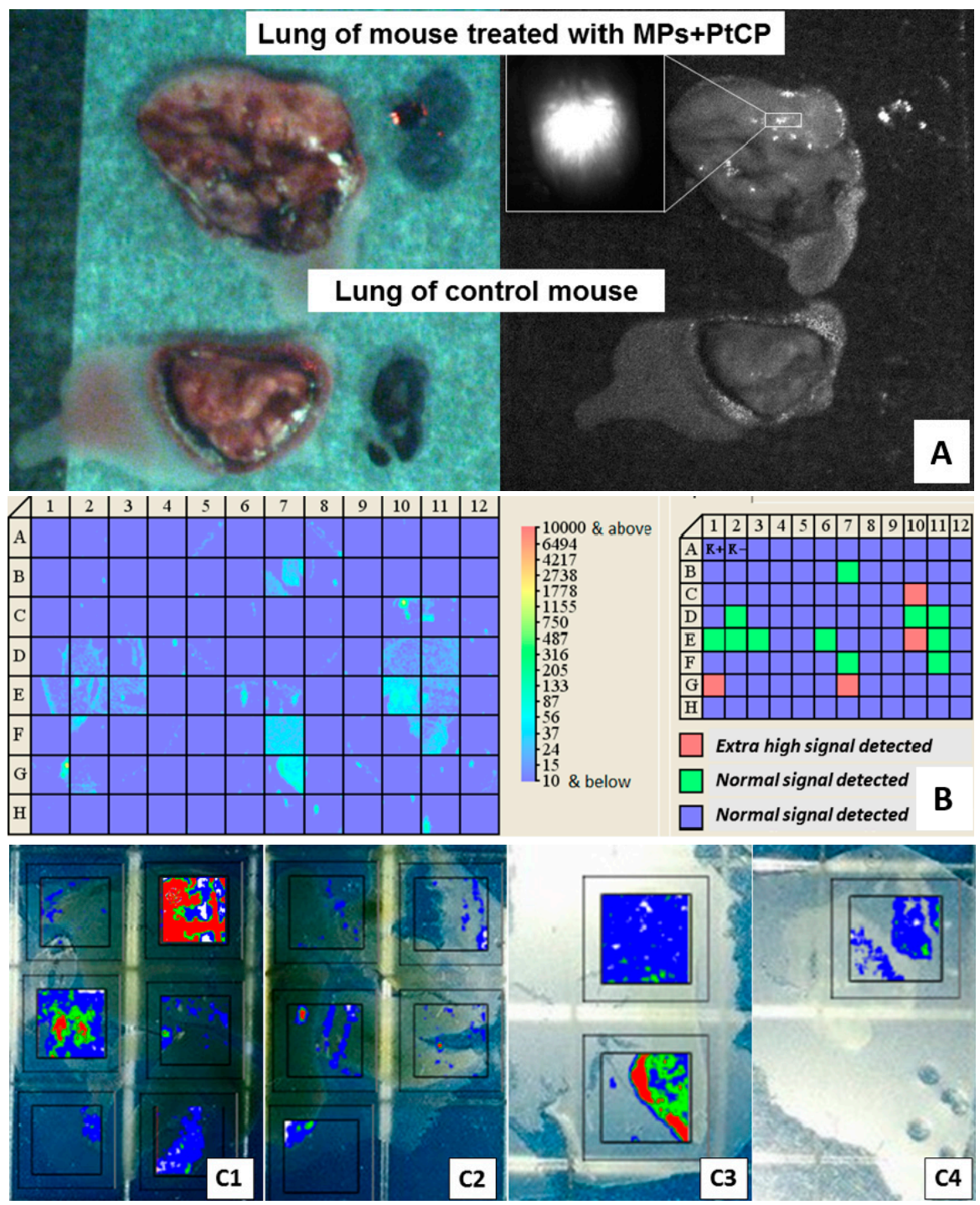

Figure 7. The results of phosphorescent platinum coproporphyrin (PtCP) luminescence on the surface (A) and within the slice of the lung (B) of mice on the seventh day after i.p. injection of particles (group MPs-IgG + PCZ i.p.) obtained with a sensitive laser fluorometric scanner diagram; (C) the comparison of tissue slices (after 50 days) luminescence of different organs: (C1) lung, group MPs-IgG + PCZ i.p.; (C2) lung, group U; (C3) liver MPs-IgG + PCZ i.p.; (C4) brain.

Table 3. Quantitative estimation of total organ slice luminescence (counts per standardized section square).

\begin{tabular}{cccc}
\hline Organ & \multicolumn{3}{c}{ Group } \\
\cline { 2 - 4 } & $\begin{array}{c}\text { U Mouse, 21st Day } \\
\text { of TB, DLD = 4.0 }\end{array}$ & $\begin{array}{c}\text { MPs + PCZ i.p. Mouse, 20th } \\
\text { Day of TB, 7th Day after } \\
\text { Injection DLD = 3.75 }\end{array}$ & $\begin{array}{c}\text { MPs-IgG + PCZ i.p. Mouse, } \\
\text { 21st Day of TB, 8th Day after } \\
\text { Injection DLD = 3.75 }\end{array}$ \\
\hline Liver & $249 \pm 27$ & $1314 \pm 144$ & $2004 \pm 220$ \\
Lung & $287 \pm 32$ & $1536 \pm 169$ & $3865 \pm 425$ \\
Spleen & $69 \pm 8$ & $238 \pm 26$ & $538 \pm 59$ \\
Brain & $30 \pm 3$ & $155 \pm 17$ & $188 \pm 21$ \\
\hline
\end{tabular}

Detection of perchlozone concentrations with LC-MS revealed higher concentrations of the drug in the lungs after intraperitoneal injection of perchlozone microparticles with camel IgG as compared to the steady-state concentration during daily multiple dose delivery of perchlozone orally (Table 4). 
Table 4. Quantitation of perchlozone in the mouse tissues with LC-MS.

\begin{tabular}{cccc}
\hline & \multicolumn{3}{c}{ Group } \\
\cline { 2 - 4 } Organ & $\begin{array}{c}\text { PCZ Concentration in } \\
\text { the Slices of PCZ per os } \\
\text { Mouse, 20th Day of TB, } \\
\text { 7th Day after Injection } \\
(\mu \mathrm{\mu g} / \mathrm{slice})\end{array}$ & $\begin{array}{c}\text { PCZ Concentration in the } \\
\text { Slices of MPs-IgG + PCZ } \\
\text { i.p. Mouse, 21st Day of } \\
\text { TB, 8th Day after } \\
\text { Injection }(\boldsymbol{\mu g} / \mathbf{s l i c e})\end{array}$ & $\begin{array}{c}\text { PCZ Concentration in the } \\
\text { Slices of [NPs-IgG + PCZ] i.v. + } \\
\text { [MPs-IgG + PCZ] i.p. Mouse, } \\
\text { 21st Day of TB, 8th Day after } \\
\text { Injection }(\boldsymbol{\mu g} / \text { slice) }\end{array}$ \\
\hline Liver & $335.2 \pm 52.8$ & $154.5 \pm 23.2$ & $297.2 \pm 44.5$ \\
Lung & $132.0 \pm 19.8$ & $283.0 \pm 42.5$ & $307.8 \pm 46.2$ \\
Spleen & $36.9 \pm 5.5$ & $59.9 \pm 9.0$ & $55.5 \pm 8.3$ \\
Brain & $1.2 \pm 0.2$ & $<0.03$ & $<0.03$ \\
\hline
\end{tabular}

\subsection{Pathomorphological Data}

We succeeded in revealing microscopic pictures typical for experimental TB in the lungs and liver (Figure 8) in all infected animals. In the group that received perchlozone orally, we observed regular nuclear hyperchromatosis (Figure 8(3)), related to the toxic effects of perchlozone [5,7]. The animals that received perchlozone within microparticles (MPs + PCZ i.p. group) demonstrated no such toxic actions (Figure 8(1,2,4)). In Figure 8(4), at low magnification, many "standard" granulomas were visible, but at magnification $(40 \times)$, no hyperchromic degenerating cells were found in the granuloma. Some polymorphism of macrophages was observed, indirectly indicating their activity. The tendency to remedial effect of the treatment with perchlozone-loaded particles was evident. In the lungs of the treated animals, we succeeded in detecting considerable amounts of exogenous light eosinophilic non-structured material in peribronchial and perivascular spaces, which were considered to be degraded particles (Figure $8(2,6)$ ).

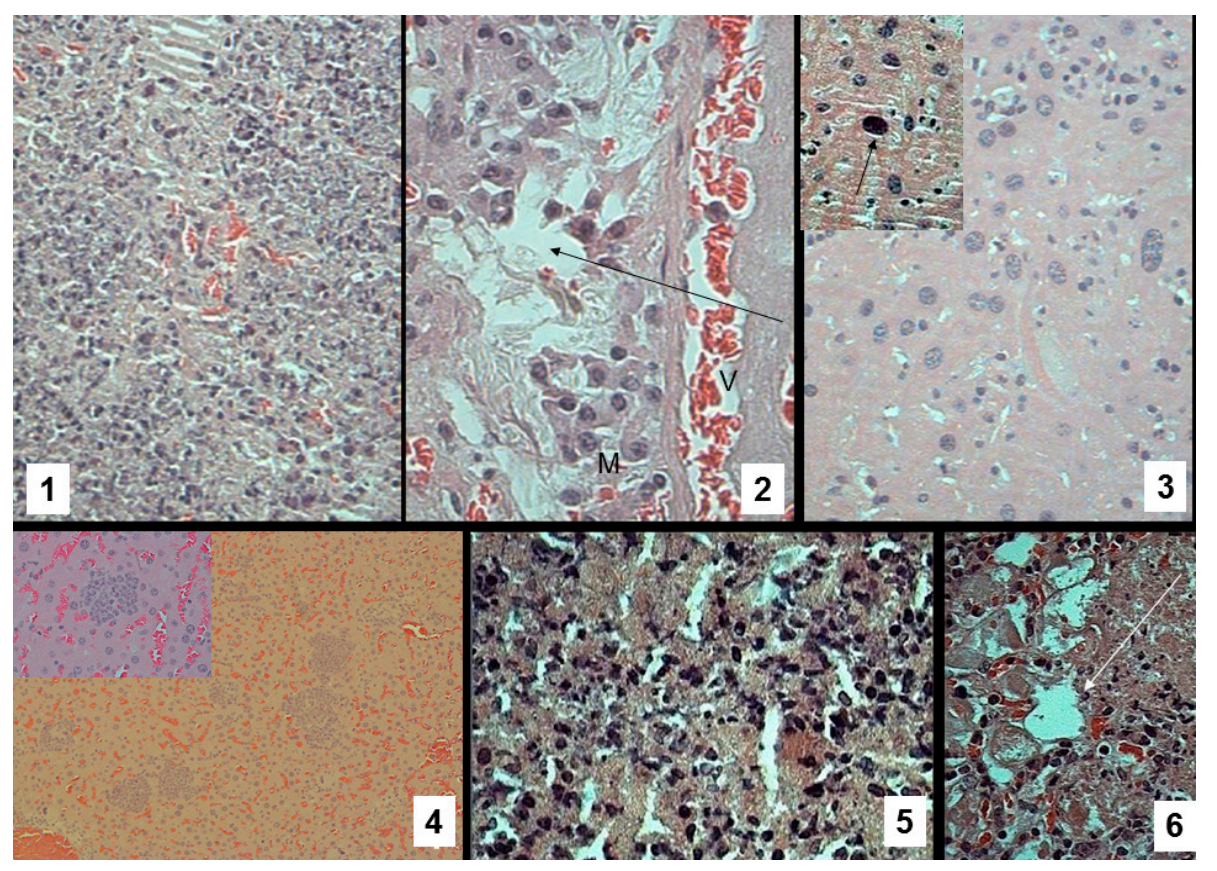

Figure 8. Pathomorphological data (hematoxylin and eosin (H\&E) stain): 1-lung, 20th day of TB, degree of macroscopic drug damage $(D L D)=3.75$, group MPs + PCZ i.p., objective 40×; 2-same animal, lung, 80×, near blood vessel (V) collection of macrophages $(M)$ and presumable deposit of particles (arrow); 3 -liver, 18th day of TB, DLD $=3.25$, group PCZ per os, $80 \times$, typical TB involvement; on top left insertion, same animal, nuclear changes (arrow) typical for PCZ toxic effect; 4-liver, 18th day of TB, DLD = 3.75, group MPs-IgG + PCZ i.p., $10 \times$ (insertion $40 \times$ ), granulomas, but no degenerating cells were found; $\mathbf{5}$ and $\mathbf{6}$-same animal as $\mathbf{1}$ and $\mathbf{2}$, lung TB, 5-objective 80×; 6-deposit of particles (arrow) in TB focus. 


\section{Discussion}

Despite previous scientific and medical efforts, tuberculosis still remains a severe disease, which kills a lot of people every day [23]. The antibiotics that are used to treat tuberculosis are often quite toxic and ineffective against resistant strains. A novel drug against the resistant forms of tuberculosis, 4-thioureidoiminomethylpyridinium perchlorate (perchlozone ${ }^{\circledR}$ ), also has serious adverse effects [5]. Therefore, we aimed to improve the delivery of perchlozone in order to reduce the side-effects.

Different particles were tested for reduction of anti-tuberculosis drug toxicity and for targeting drugs into macrophages $[18,43]$. Nevertheless, the particles in these studies were delivered via a pulmonary route to target macrophages in the lung. Most studies dealt with encapsulation of old drugs like rifampicin [15], ofloxacin [18], and dexamethasone [43]. We report here the properties of encapsulated forms of a new drug with activity against resistant tuberculosis.

The idea of our study was to apply the non-inflamed macrophages from intraperitoneal fluid as delivery vehicles of the novel drug perchlozone, to treat MDR-TB. We propose that PLA-based particles, which were internalized by peritoneal macrophages, move to the inflammation site in the lung via chemotaxis. In this way, the systemic distribution of perchlozone could be reduced and efficacy of the drug could be improved.

Perchlozone was successfully loaded into PLA micro- and nanoparticles using modified double emulsion and nanoprecipitation methods, respectively. Perchlozone is a quite a hydrophilic drug, and its encapsulation efficiency into microparticles via emulsification approach was initially low, presumably due to the instability of the water-in-oil emulsion. The loading was improved with surfactant with low hydrophilic/lipophilic balance number (lecithin with HLB $=4$ ). Successful entrapment of perchlozone was proven photometrically and with FTIR spectroscopy. Importantly, XRD studies did not show any separate perchlozone phases in the particles, suggesting that the drug was homogenously dispersed into the PLA matrix. The encapsulation of perchlozone via nanoprecipitation resulted in slightly greater efficacy, which could be explained by rapid PLA phase separation and trapping of drug molecules inside the precipitated particles. As far as we know, this is the first study that combines micro- and nanoparticles for treatment of tuberculosis.

The particle degradation and perchlozone release were studied in a medium that mimics the environment in the macrophages. The obtained results (Figure 2) suggest that particles could be stable in the phagocytes for 10 days, which is adequate time for the transfer of macrophages to the inflammation sites in the lungs. In general, based on the results, we propose that a substantial drug quantity is delivered within macrophages to the foci of infection.

Camel IgG is known to be a good therapeutic agent itself [44,45]. Here, it was applied for macrophage targeting, but its own therapeutic activity against tuberculosis is also possible. Both microand nanoparticles were successfully modified by camel IgG via activated ester approach, and the conjugated camel $\operatorname{IgG}$ induced opsonization and activated the phagocytosis of the particles (Figure 4). Not surprisingly, microparticles were phagocytosed more extensively than the nanoparticules (Figure 4). It was previously shown that microparticles are better recognized by macrophages than nanosized structures [46].

The experiments with infected mice showed that application of particulate formulations of perchlozone, especially IgG-modified particles, were more effective (animal survival improved) at clearly lower total doses than oral percholozone. A lower degree of lung damage in survived mice was also seen in mice that received injected perchlozone particles. It is noteworthy that the total dose of perchlozone in the injected particles was $44 \mathrm{mg} / \mathrm{kg}$ (Table 1), only $7.3 \%$ of the dose that was delivered orally. The data suggest that particle-encapsulated perchlozone is delivered to the lungs within the macrophages.

The results were obtained with the application of outbred mice to mimic the genetic diversity in the human population in terms of immune responses to mycobacterial infection and drug pharmacokinetics. Despite the fact that many interesting results were obtained with the application of inbred mice [47], the application of outbred animals allowed us to test the targeting capabilities of 
macrophages, which do not have the same genetic defects as in the inbred mice [35]. However, one could expect even better survival with C57Bl/6 mice [28], and we are going to test this further.

Biodistribution of microparticles and perchlozone cargo was studied using fluorescent labeling (Figure 7, Table 3) and LC-MS analysis of tissue slices, respectively. The PtCP label was detected in the infected lungs suggesting particle delivery, possibly via macrophage chemotaxis. This is consistent with the pathomorphological data. Microparticles do not diffuse from the peritoneal cavity to the blood stream as such, but tend to accumulate there [48], which also supports the notion of macrophage-mediated transport. The LC-MS data showed the highest concentrations of perchlozone in the lungs as compared with the other organs, proving effective drug delivery to the lungs. It should also be noted that the microparticles (possibly with $\operatorname{IgG}$ ) are suitable for intraperitoneal injections, because they can be internalized by macrophages for further chemotaxis $[49,50]$. However, the resolution of images (Figures 7 and 8(6)) allows us to make only preliminary conclusions on the particles' pharmacokinetics, and further studies are required to obtain more detailed information.

The pathomorphological data comparison (Figure 8) with the evidence on perchlozone concentrations in the organs of experimental animals (Table 4) allows the conclusion that oral administration of drug results in high drug concentration in the liver. This causes the hepatotoxicity of the drug. Intravenously administered nanoparticles seem to also deliver drugs to the liver (Table 4). However, after nanoparticle administration, the drug may not be fully released in the liver and its distribution within the liver may differ from the distribution of orally administered perchlozone. The best therapeutic effect with minimal toxicity (Figure $8(4)$ ) was seen after application of perchlozone-loaded microparticles intraperitoneally. This favorable effect and minimal toxicity was probably due to macrophage-mediated transport to the foci of inflammation in the lungs, avoidance of the first pass metabolism, and differences of drug distribution in the liver (among cell types, encapsulated vs. free drug). We also need to mention that possible hepatotoxic effects of perchlozone alone after i.p. and i.v. administration were not tested.

\section{Conclusions}

The PLA-based micro- and nanoparticles were loaded with anti-tuberculosis drug perchlozone, and successfully applied for treatment of MDR-TB in mice. The best survival was observed in animals that were treated with intravenous IgG-modified nanoparticles and intraperitoneal IgG-modified microparticles, both loaded with perchlozone. Targeted particle delivery to the foci of infection in tuberculosis mice was seen. The observed greater longevity of treated experimental mice could be attributed to the application of PLA-based perchlozone-loaded microparticles, modified by camel IgG.

Further studies are needed to understand the pathways and mechanisms of particle distribution in the body. Nevertheless, the applied treatment could be proposed for MDR-TB so as to decrease the drug toxicity.

Supplementary Materials: The following is available online at http:/ /www.mdpi.com/1999-4923/11/1/2/s1: Figure S1: The linearization of perchlozone release plots.

Author Contributions: L.C., O.D., P.Y., A.U., and T.T. conceptualized the work and organized it within their groups. A.U. and T.T. are the leading scientists of the Megagrant from the Government of the Russian Federation, which allowed the experiments. They participated in all discussions and corrected the manuscript at each stage of its preparation. L.C. and O.D. planned the animal experiments and controlled their processing. L.C. participated in euthanized mice dissection and analysis of pathomorphological data. O.D. participated in LC-MS analysis of the drug in the slices of the mice and discussion of results. V.K.-V. suggested the particles for idea implementation, prepared the drug-loaded micro- and nanoparticles, and performed the characterization of particles. The drug release curves linearization was also performed by V.K.-V. E.S. studied the release of the drug and performed the camel IgG attachment to the particle surface. G.P. was responsible for the camel IgG separation and purification. T.V., N.Z., and M.P. were the main performers of all animal experiments in vivarium. They also participated in the preparation of slices for analysis. P.Y. managed this work as Director of the Institute and participated in discussions. Dmitry Polyakov performed the in vitro phagocytosis evaluation and confocal microscopy measurements. V.U. and V.Z. performed the histological pathomorphological studies. V.K.-V., L.C., A.U., and T.T. prepared the manuscript. All authors approved the final version of the paper. 
Funding: The chemical part of the research, i.e., the synthesis of the polymer, preparation of the encapsulated perchlozone formulation, release studies, and camel IgG purification and attachment, was financially supported by the Russian Scientific Foundation (\#14-50-00069/05-109). The biomedical studies, i.e., phagocytosis evaluation, detection of PtCP in slices, LC-MS etc., were funded by the Russian Ministry of Science (Megagrant \#14.W03.31.0025). The animal laboratory work was also supported by the Ministry of Health of the Russian Federation within the State Task.

Acknowledgments: The authors are grateful to the Scientific Park of St. Petersburg State University, especially to the center of X-ray diffraction studies for powder XRD measurements, Geomodel resource center for SEM images, Center for Optical and Laser Materials Research for FTIR measurements, and Magnetic Resonance Research Center for NMR spectra recording.

Conflicts of Interest: The authors declare no conflicts of interest regarding this research.

\section{Abbreviations}

$\begin{array}{ll}\text { TB } & \text { tuberculosis } \\ \text { HIV } & \text { human immunodeficiency virus } \\ \text { MDR-TB } & \text { multiple drug resistant } M \text {. tuberculosis } \\ \text { PLA } & \text { poly(D,L-lactic acid) } \\ \text { ICG } & \text { indocyanine green } \\ \text { IgG } & \text { immunoglobulin G } \\ \text { PtCP } & \text { platinum(II)-coproporphyrin } \\ \text { CFU } & \text { colony-forming units } \\ \text { LC-MS } & \text { liquid chromatography/mass spectrometry }\end{array}$

\section{References}

1. Dye, C. After 2015: Infectious diseases in a new era of health and development. Philos. Trans. R. Soc. B Biol. Sci. 2014, 369, 20130426. [CrossRef] [PubMed]

2. Lienhardt, C.; Raviglione, M.; Spigelman, M.; Hafner, R.; Jaramillo, E.; Hoelscher, M.; Zumla, A.; Gheuens, J. New drugs for the treatment of tuberculosis: Needs, challenges, promise, and prospects for the future. J. Infect. Dis. 2012, 205, S241-S249. [CrossRef] [PubMed]

3. Trinh, Q.M.; Nguyen, H.L.; Nguyen, V.N.; Nguyen, T.V.A.; Sintchenko, V.; Marais, B.J. Tuberculosis and HIV co-infection-focus on the Asia-Pacific region. Int. J. Infect. Dis. 2015, 32, 170-178. [CrossRef] [PubMed]

4. WHO. Global Tuberculosis Report 2014; WHO: Geneva, Switzerland, 2014; Volume 2014, ISBN 9789241564809.

5. Chernokhaeva, I.; Pavlova, M.; Starshinova, A.; Sapozhnikova, N.; Belaeva, E.; Zhuravlev, V.; Archakova, L.; Yablonskii, P.; Starshinova, A. Therapy of pulmonary tuberculosis with multidrug-resistant Mycobacterium tuberculosis using tioureidoiminomethylpyridinium perchlorate (Perchlozon). Int. J. Tech. Res. Appl. 2015, 3, $59-62$.

6. Gopal, P.; Dick, T. The new tuberculosis drug Perchlozone ${ }^{\circledR}$ shows cross-resistance with thiacetazone. Int. J. Antimicrob. Agents 2015, 45, 430-433. [CrossRef] [PubMed]

7. Pavlova, M.; Vinogradova, T. Confirmation of preclinical studies data on perchlorate (Perchlozon) in clinic. Int. J. Curr. Res. 2015, 7, 14501-14505.

8. Kalita, S.; Devi, B.; Kandimalla, R.; Sharma, K.K.; Sharma, A.; Kalita, K.; Kataki, A.C.; Kotoky, J.

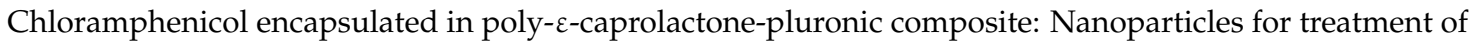
MRSA-infected burn wounds. Int. J. Nanomed. 2015, 10, 2971-2984. [CrossRef]

9. Lboutounne, H.; Chaulet, J.-F.; Ploton, C.; Falson, F.; Pirot, F. Sustained ex vivo skin antiseptic activity of chlorhexidine in poly(epsilon-caprolactone) nanocapsule encapsulated form and as a digluconate. J. Control. Release 2002, 82, 319-334. [CrossRef]

10. Rishi, P.; Bhogal, A.; Arora, S.; Pandey, S.K.; Verma, I.; Kaur, I.P. Improved oral therapeutic potential of nanoencapsulated cryptdin formulation against Salmonella infection. Eur. J. Pharm. Sci. 2015, 72, 27-33. [CrossRef]

11. Pandey, R.; Sharma, A.; Zahoor, A.; Sharma, S.; Khuller, G.K.; Prasad, B. Poly(DL-lactide-co-glycolide) nanoparticle-based inhalable sustained drug delivery system for experimental tuberculosis. J. Antimicrob. Chemother. 2003, 52, 981-986. [CrossRef] 
12. Sharma, R.; Saxena, D.; Dwivedi, A.K.; Misra, A. Inhalable microparticles containing drug combinations to target alveolar macrophages for treatment of pulmonary tuberculosis. Pharm. Res. 2001, 18, 1405-1410. [CrossRef] [PubMed]

13. Garg, T.; Rath, G.; Goyal, A.K. Inhalable chitosan nanoparticles as antitubercular drug carriers for an effective treatment of tuberculosis. Artif. Cells Nanomed. Biotechnol. 2015, 1-5. [CrossRef]

14. Parikh, R.; Patel, L.; Dalwadi, S. Microparticles of rifampicin: Comparison of pulmonary route with oral route for drug uptake by alveolar macrophages, phagocytosis activity and toxicity study in albino rats. Drug Deliv. 2013, 7544, 1-6. [CrossRef] [PubMed]

15. Jain, S.K.; Gupta, Y.; Ramalingam, L.; Jain, A.; Jain, A.; Khare, P.; Bhargava, D. Lactose-Conjugated PLGA Nanoparticles for Enhanced Delivery of Rifampicin to the Lung for Effective Treatment of Pulmonary Tuberculosis. PDA J. Pharm. Sci. Technol. 2010, 64, 278-287. [PubMed]

16. Dheda, K.; Schwander, S.K.; Zhu, B.; Van Zyl-Smit, R.N.; Zhang, Y. The immunology of tuberculosis: From bench to bedside. Respirology 2010, 15, 433-450. [CrossRef]

17. Amarnath Praphakar, R.; Munusamy, M.A.; Sadasivuni, K.K.; Rajan, M. Targeted delivery of rifampicin to tuberculosis-infected macrophages: Design, in-vitro, and in-vivo performance of rifampicin-loaded poly(ester amide)s nanocarriers. Int. J. Pharm. 2016, 513, 628-635. [CrossRef]

18. Hwang, S.M.; Kim, D.D.; Chung, S.J.; Shim, C.K. Delivery of ofloxacin to the lung and alveolar macrophages via hyaluronan microspheres for the treatment of tuberculosis. J. Control. Release 2008, 129, 100-106. [CrossRef]

19. Takenaga, M.; Ohta, Y.; Tokura, Y.; Hamaguchi, A.; Igarashi, R.; Disratthakit, A.; Doi, N. Lipid Microsphere Formulation Containing Rifampicin Targets Alveolar Macrophages. Drug Deliv. 2008, 15, 169-175. [CrossRef]

20. Yoshida, A.; Matumoto, M.; Hshizume, H.; Oba, Y.; Tomishige, T.; Inagawa, H.; Kohchi, C.; Hino, M.; Ito, F.; Tomoda, K.; et al. Selective delivery of rifampicin incorporated into poly(DL-lactic-co-glycolic) acid microspheres after phagocytotic uptake by alveolar macrophages, and the killing effect against intracellular Mycobacterium bovis Calmette-Guérin. Microbes Infect. 2006, 8, 2484-2491. [CrossRef]

21. Horváti, K.; Bacsa, B.; Szabó, N.; Dávid, S.; Mezo, G.; Grolmusz, V.; Vértessy, B.; Hudecz, F.; Bo'sze, S. Enhanced cellular uptake of a new, in silico identified antitubercular candidate by peptide conjugation. Bioconjug. Chem. 2012, 23, 900-907. [CrossRef]

22. Horváti, K.; Bacsa, B.; Kiss, É.; Gyulai, G.; Fodor, K.; Balka, G.; Rusvai, M.; Szabó, E.; Hudecz, F.; Bősze, S. Nanoparticle Encapsulated Lipopeptide Conjugate of Antitubercular Drug Isoniazid: In Vitro Intracellular Activity and in Vivo Efficacy in a Guinea Pig Model of Tuberculosis. Bioconjug. Chem. 2014, 25, 2260-2268. [CrossRef] [PubMed]

23. Shivangi; Meena, L.S. A Novel Approach in Treatment of Tuberculosis by Targeting Drugs to Infected Macrophages Using Biodegradable Nanoparticles. Appl. Biochem. Biotechnol. 2018, 185, 815-821. [CrossRef] [PubMed]

24. Wang, Q.; Cheng, H.; Peng, H.; Zhou, H.; Li, P.Y.; Langer, R. Non-genetic engineering of cells for drug delivery and cell-based therapy. Adv. Drug Deliv. Rev. 2015, 91, 125-140. [CrossRef] [PubMed]

25. Banskota, S.; Yousefpour, P.; Chilkoti, A. Cell-Based Biohybrid Drug Delivery Systems: The Best of the Synthetic and Natural Worlds. Macromol. Biosci. 2017, 17, 1-16. [CrossRef] [PubMed]

26. Korzhikov, V.; Averianov, I.; Litvinchuk, E.; Tennikova, T.B. Polyester-based microparticles of different hydrophobicity: The patterns of lipophilic drug entrapment and release. J. Microencapsul. 2016, 33, 199-208. [CrossRef] [PubMed]

27. Cardona, P.J.; Cooper, A.; Luquín, M.; Ariza, A.; Filipo, F.; Orme, I.M.; Ausina, V. The intravenous model of murine tuberculosis is less pathogenic than the aerogenic model owing to a more rapid induction of systemic immunity. Scand. J. Immunol. 1999, 49, 362-366. [CrossRef] [PubMed]

28. Nuermberger, E. Using Animal Models to Develop New Treatments for Tuberculosis. Semin. Respir. Crit. Care Med. 2008, 29, 542-551. [CrossRef]

29. Guryanov, I.; Cipriani, S.; Fiorucci, S.; Zashikhina, N.; Marchianò, S.; Scarpelli, P.; Korzhikov-Vlakh, V.; Popova, E.; Korzhikova-Vlakh, E.; Biondi, B.; et al. Nanotraps with Biomimetic Surface as Decoys for Chemokines. Nanomed. Nanotechnol. Biol. Med. 2017. [CrossRef]

30. Costa, P.; Sousa Lobo, J.M. Modeling and comparison of dissolution profiles. Eur. J. Pharm. Sci. 2001, 13, 123-133. [CrossRef]

31. Salome, A.C.; Godswill, C.O.; Ikechukwu, I.O. Kinetics and mechanisms of drug release from swellable and non swellable matrices: A review. Res. J. Pharm. Biol. Chem. Sci. 2013, 4, 97-103. [CrossRef] 
32. Twair, A.; Al-Okla, S.; Zarkawi, M.; Abbady, A.Q. Characterization of camel nanobodies specific for superfolder GFP fusion proteins. Mol. Biol. Rep. 2014. [CrossRef] [PubMed]

33. Reiner, N.E. (Ed.) Macrophages and Dendritic Cells: Methods and Protocols; Methods in Molecular Biology; Humana Press: New York, NY, USA, 2009; Volume 531, ISBN 978-1-58829-972-7.

34. Freebern, W.J.; Bigwarfe, T.J.; Price, K.D.; Haggerty, H.G. Methods: Implementation of in vitro and ex vivo phagocytosis and respiratory burst function assessments in safety testing. J. Immunotoxicol. 2013, 10, 106-117. [CrossRef] [PubMed]

35. Papkovsky, D.B.; O'Riordan, T.C. Emerging applications of phosphorescent metalloporphyrins. J. Fluoresc. 2005, 15, 569-584. [CrossRef] [PubMed]

36. Almeida, F.M.; Ventura, T.L.B.; Amaral, E.P.; Ribeiro, S.C.M.; Calixto, S.D.; Manhães, M.R.; Rezende, A.L.; Souzal, G.S.; De Carvalho, I.S.; Silva, E.C.; et al. Hypervirulent Mycobacterium tuberculosis strain triggers necrotic lung pathology associated with enhanced recruitment of neutrophils in resistant C57BL/6 mice. PLoS ONE 2017, 12, 1-19. [CrossRef]

37. Martín-Hernando, M.P.; Höfle, U.; Vicente, J.; Ruiz-Fons, F.; Vidal, D.; Barral, M.; Garrido, J.M.; de la Fuente, J.; Gortazar, C. Lesions associated with Mycobacterium tuberculosis complex infection in the European wild boar. Tuberculosis 2007, 87, 360-367. [CrossRef]

38. Ordonez, A.A.; Tasneen, R.; Pokkali, S.; Xu, Z.; Converse, P.J.; Klunk, M.H.; Mollura, D.J.; Nuermberger, E.L.; Jain, S.K. Mouse model of pulmonary cavitary tuberculosis and expression of matrix metalloproteinase-9. Dis. Model. Mech. 2016, 9, 779-788. [CrossRef] [PubMed]

39. Radaeva, T.V.; Kondratieva, E.V.; Sosunov, V.V.; Majorov, K.B.; Apt, A. A human-like TB in genetically susceptible mice followed by the true dormancy in a Cornell-like model. Tuberculosis 2008, 88, 576-585. [CrossRef]

40. Zabolotnykh, N.V.; Vinogradova, T.I.; Stukova, M.A.; Vasil'eva, S.N.; Vitovskaia, M.L.; Egorov, A.I. The effectiveness of influenza vectors expressing the protective mycobacterial antigen ESAT-6 in the complex therapy of generalized tuberculosis in mice. Probl. Tuberk. Bolezn. Legk. 2008, 12, 30-34.

41. Lee, E.; Wang, J.; Kleinbaum, D.G.; Collett, D. Statistical Methods for Survival Data Analysis; John Wiley \& Sons: Hoboken, NJ, USA, 2003; Volume 36, ISBN 3175723993.

42. Ray, K.; Szmacinski, H.; Chowdhury, M.H.; Lakowicz, J.R. Metal-enhanced intrinsic fluorescence of proteins and label-free bioassays. In Proceedings of the Plasmonics in Biology and Medicine VII, San Francisco, CA, USA, 23-28 January 2010; p. 75770K.

43. Zhao, C.; Fan, T.; Yang, Y.; Wu, M.; Li, L.; Zhou, Z.; Jian, Y.; Zhang, Q.; Huang, Y. Preparation, macrophages targeting delivery and anti-inflammatory study of pentapeptide grafted nanostructured lipid carriers. Int. J. Pharm. 2013, 450, 11-20. [CrossRef] [PubMed]

44. Cook, D.A.N.; Samarasekara, C.L.; Wagstaff, S.C.; Kinne, J.; Wernery, U.; Harrison, R.A. Analysis of camelid IgG for antivenom development: Immunoreactivity and preclinical neutralisation of venom-induced pathology by IgG subclasses, and the effect of heat treatment. Toxicon 2010, 56, 596-603. [CrossRef]

45. Shaker, G.H. Evaluation of antidiphtheria toxin nanobodies. Nanotechnol. Sci. Appl. 2010, 3, 29-35. [CrossRef] [PubMed]

46. Tabata, Y.; Ikada, Y. Effect of the size and surface charge of polymer microspheres on their phagocytosis by macrophage. Biomaterials 1988, 9, 356-362. [CrossRef]

47. Nikonenko, B.; Sacksteder, K.; Hundert, S.; Einck, L.; Nacy, C. Preclinical Study of New TB Drugs and Drug Combinations in Mouse Models. Recent Pat. Antiinfect. Drug Discov. 2008, 3, 102-116. [CrossRef] [PubMed]

48. Lu, Z.; Tsai, M.; Lu, D.; Wang, J.; Wientjes, M.G.; Au, J.L.-S. Tumor-Penetrating Microparticles for Intraperitoneal Therapy of Ovarian Cancer. J. Pharmacol. Exp. Ther. 2008, 327, 673-682. [CrossRef] [PubMed]

49. Iqbal, A.J.; Regan-Komito, D.; Christou, I.; White, G.E.; McNeill, E.; Kenyon, A.; Taylor, L.; Kapellos, T.S.; Fisher, E.A.; Channon, K.M.; et al. A Real Time Chemotaxis Assay Unveils Unique Migratory Profiles amongst Different Primary Murine Macrophages. PLoS ONE 2013, 8. [CrossRef]

50. Green, T.D.; Park, J.; Yin, Q.; Fang, S.; Crews, A.L.; Jones, S.L.; Adler, K.B. Directed migration of mouse macrophages in vitro involves myristoylated alanine-rich C-kinase substrate (MARCKS) protein. J. Leukoc. Biol. 2012, 92, 633-639. [CrossRef]

(C) 2018 by the authors. Licensee MDPI, Basel, Switzerland. This article is an open access article distributed under the terms and conditions of the Creative Commons Attribution (CC BY) license (http:/ / creativecommons.org/licenses/by/4.0/). 